\title{
Risk factors associated with mechanical ventilation, autonomic nervous dysfunction and physical outcome in Vietnamese adults with tetanus
}

Rachel Davies-Foote ${ }^{1 \dagger}$, Truong Ngoc Trung ${ }^{2 \dagger}$, Nguyen Van Thanh Duoc ${ }^{2 \dagger}$, Du Hong Duc ${ }^{3}$, Phung Tran Huy Nhat ${ }^{3,4}$, Vo Thi Nhu Trang ${ }^{5}$, Nguyen Thi Kim Anh², Pham Thi Lieu ${ }^{3}$, Duong Bich Thuy², Nguyen Thanh Phong², Nguyen Thanh Truong2, Pham Ba Thanh², Dong Thi Hoai Tam, ${ }^{3,6}$ Tran Thi Diem Thuy², Pham Thi Tuyen², Thanh Tran Tan ${ }^{3}$, James Campbell ${ }^{3,7}$, Le Van Tan³ ${ }^{3}$ Zudin Puthucheary ${ }^{8,9}$, Lam Minh Yen ${ }^{3}$, Nguyen Van Hao ${ }^{2,6}$ and C. Louise Thwaites T, $^{3, *}$

\begin{abstract}
Background: Tetanus remains common in many low- and middle-income countries, but as critical care services improve, mortality from tetanus is improving. Nevertheless, patients develop severe syndromes associated with autonomic nervous system disturbance (ANSD) and the requirement for mechanical ventilation (MV). Understanding factors associated with worse outcome in such settings is important to direct interventions. In this study, we investigate risk factors for disease severity and long-term physical outcome in adults with tetanus admitted to a Vietnamese intensive care unit.

Methods: Clinical and demographic variables were collected prospectively from 180 adults with tetanus. Physical function component scores (PCS), calculated from Short Form Health Survey (SF-36), were assessed in 79 patients at hospital discharge, 3 and 6 months post discharge.

Results: Age, temperature, heart rate, lower peripheral oxygen saturation $\left(\mathrm{SpO}_{2}\right)$ and shorter time from first symptom to admission were associated with MV (OR 1.03 [ 95\% confidence interval (Cl) 1.00, 1.05], $p=0.04$; OR 2.10 [95\% Cl 1.03, 4.60], $p=0.04 ; \mathrm{OR} 1.04$ [ $95 \% \mathrm{Cl} 1.01,1.07], p=0.02) ; \mathrm{OR} 0.80$ [95\% Cl 0.66, 0.94], $p=0.02$ and OR 0.65 [95\% Cl 0.52, 0.79, $p<$ 0.001 , respectively).

Heart rate, $\mathrm{SpO}_{2}$ and time from first symptom to admission were associated with ANSD (OR 1.03 [95\% Cl 1.01, 1.06], $p<$ $0.01 ; \mathrm{OR} 0.95$ [95\% Cl 0.9, 1.00], $p=0.04$ and OR 0.64 [95\% Cl 0.48, 0.80], $p<0.01$, respectively).

Median [interquartile range] PCS at hospital discharge, 3 and 6 months were 32.37 [24.95-41.57, 53.0 [41.6-56.3] and 54.8

[51.6-57.3], respectively. Age, female sex, admission systolic blood pressure, admission $\mathrm{SpO}_{2}, \mathrm{MV}$, ANSD, midazolam requirement, hospital-acquired infection, pressure ulcer and duration of ICU and hospital stay were associated with reduced 0.25 quantile PCS at 6 months after hospital discharge.
\end{abstract}

\footnotetext{
*Correspondence: Ithwaites@oucru.org

${ }^{\dagger}$ Rachel Davies-Foote, Truong Ngoc Trung and Nguyen Van Thanh Duoc share joint authorship.

${ }^{3}$ Oxford University Clinical Research Unit, Ho Chi Minh City, Vietnam

${ }^{7}$ Centre for Tropical Medicine and Global Health, University of Oxford,

Oxford, UK

Full list of author information is available at the end of the article
}

(c) The Author(s). 2021 Open Access This article is licensed under a Creative Commons Attribution 4.0 International License, which permits use, sharing, adaptation, distribution and reproduction in any medium or format, as long as you give appropriate credit to the original author(s) and the source, provide a link to the Creative Commons licence, and indicate if changes were made. The images or other third party material in this article are included in the article's Creative Commons licence, unless indicated otherwise in a credit line to the material. If material is not included in the article's Creative Commons licence and your intended use is not permitted by statutory regulation or exceeds the permitted use, you will need to obtain permission directly from the copyright holder. To view a copy of this licence, visit http://creativecommons.org/licenses/by/4.0/. 
Conclusions: MV and ANSD may be suitable endpoints for future research. Risk factors for reduced physical function at 3 months and 6 months post discharge suggest that modifiable features during hospital management are important determinants of long-term outcome.

Keywords: Tetanus, Clostridium tetani, Tetanus toxin, Acute critical illness, Vietnam, Low-income and middle-income countries (LMICs), Severity, Long-term outcome, Physical function

\section{Background}

Tetanus is a vaccine-preventable disease associated with severe muscle spasm and cardiovascular system disturbance that remains a common cause of acute critical illness in low- and middle-income countries (LMICs) [1].

As critical care services improve throughout the world, the capacity to manage severe tetanus is increasing and some centres have reported significant reductions in mortality rates [2-4]. Nevertheless, patients still experience severe muscle spasms necessitating prolonged treatment with muscle relaxants and mechanical ventilation in addition to cardiovascular instability and autonomic nervous system dysfunction (ANSD) [5].

Historical literature contains many studies documenting risk factors for mortality in tetanus when muscle spasm were the principal causes of death [6,7]. It is unclear whether these same risk factors are important in modern ICU settings where death due to respiratory muscle spasms can be prevented by mechanical ventilation $[5,8]$. Furthermore, as mortality rates decrease, predicting those at risk of other outcomes such as mechanical ventilation or ANSD may be more relevant to everyday clinical practice and clinical trial outcomes $[9,10]$.

As survivorship improves, understanding the quality of life of survivors is increasingly important but is much neglected in published literature, particularly in LMIC settings. There is very little known about disability in tetanus survivors although this is particularly important as in most countries tetanus affects mainly men of working age where long-term disability might have a significant social and economic impact. The limited data that do exist suggest a significant number of survivors are left with impairment. In a retrospective study of adults with tetanus admitted to intensive care units (ICUs) in France, out of 38 survivors with a known functional status at follow-up, $39 \%$ suffered worsening of functional impairment compared to before admission, whilst $17 \%$ required admission to a long-term care facility [11]. In a Japanese case series, $35 \%$ of all survivors were discharged from hospital to a facility other than home [12]. Muscle wasting has been identified as an important factor contributing to ICUrelated functional impairment [13]. We have previously reported significant muscle wasting during hospitalisation in adults with tetanus, the degree of which was related to age, occurrence of hospital-acquired infection, and subsequent health-related quality of life scores [14].
We examine what factors predict more severe disease and also what factors are associated with physical disability at hospital discharge, 3 and 6 months post hospital discharge. This information is an important step to improving tetanus outcome in other centres and understanding more about long-term effects of critical illness in low- and middle-income countries.

\section{Methods}

The study was performed at the Hospital for Tropical Diseases (HTD), Ho Chi Minh City. The hospital is a tertiary referral centre for infectious diseases serving Southern Vietnam. Patients were treated according to a standard protocol as previously described [15]. Briefly, this consists of antibiotics and antitoxin; spasm control with benzodiazepeines (midazolam or diazepam) escalated to non-depolarising muscle relaxants (pipecuronium) and mechanical ventilation. Airway management is by primary tracheostomy with the following indications: laryngeal spasms compromising the airway, sputum retention and to facilitate mechanical ventilation. ANSD is managed with magnesium sulphate and additional calcium antagonists or inotropes as clinically indicated. All patients receive a full primary course of tetanus-toxoid containing vaccine initiated at discharge. ANSD was defined as at least 3 of (i) heart rate $>100$ beats per minute (bpm), (ii) systolic blood pressure > $140 \mathrm{mmHg}$, (iii) mean arterial pressure $<60 \mathrm{mmHg}$, (iv) pyrexia $>38^{\circ} \mathrm{C}$, and (v) fluctuating blood pressure, occurring within one day with no other apparent cause [16].

Investigation of risk factors for tetanus severity was carried out with prospectively collected data from two cohorts of patients $\geq 16$ years old admitted to the hospital's ICU with a diagnosis of generalised tetanus: from August 2016 to March 2017 and January to July 2018, described elsewhere [14]. Physical functional outcome was evaluated in the subgroup of patients enrolled between August 2016 and March 2017 in whom there were 2 exclusion criteria: not speaking Vietnamese and unable to walk before admission. The Study Flowchart is shown in Additional File 1.

Data were collected prospectively daily by study staff in all enrolled subjects. A core dataset of recognised tetanus prognostic features, basic clinical and demographic data were collected in both cohorts Additionally patients 
were followed daily for complications and interventions such as MV by study staff. Treatment for hospitalacquired infections of ventilator-associated pneumonia, urinary tract infection and bacteraemia were specifically evaluated in these daily observations. Diagnosis and treatment of these followed local hospital guidelines. In the physical outcome subgroup, physical function was assessed using the physical component summary score (PCS) derived from the RAND 36-item Short Form Health Survey (SF-36) version 1 completed at hospital discharge by face-to-face interview, 3 months post discharge and 6 months post discharge by telephone interview [17]. Using the method described by Ware et al., individual question scores were transformed and averaged to the eight aggregate scale (domain) scores and, from these, the PCS was calculated [18]. This method results in a single PCS for each patient, calculated by differentially weighting then combining the scale scores and applying a linear transformation. Applying this methodology to the US population data results in a mean PCS of 50 with a standard deviation of 10 . Standard US scores were used for PCS calculation as no validated Vietnamese population standard scores exist.

\section{Statistical analysis}

Descriptive statistics were used to describe the sample with the median and interquartile range (IQR) for continuous data, and count and percentage for categorical data. Univariate logistic regression was used to examine associations between ANSD and each of the demographic and baseline clinical features. Features were selected based on the availability in the core dataset (i.e. both cohorts of patients) and clinical plausibility associated with known prognostic indicators in tetanus. Baseline features selected were age, gender, entry site, incubation period, period of onset, time from first symptom to first spasm and symptom of difficulty breathing on admission. Clinical features on admission were taken as the worst value in the first $24 \mathrm{~h}$ : highest heart rate, heart rate range, maximum systolic blood pressure and temperature, peripheral oxygen saturation $\left(\mathrm{SpO}_{2}\right)$, serum creatinine, platelet count, white blood cell count, urine output and Ablett score. Briefly, Ablett scores the severity of tetanus according to spasms (grade 1 no spasms, 2 mild spasms, 3 spasms interfering with respiration) and additional clinical autonomic disturbance (grade 4) [19]. Variables that were associated with ANSD in the univariate analysis were entered into a multivariate logistic regression model using a backward approach dropping one least significant variable at a time. A backward approach was selected due to the large number of potential covariates and to reduce issues related to multiple collinearity. The major assumptions of logistic regression including the linearity assumption, multicollinearity and influential values were checked for the models.
The same strategy as outlined above was used to evaluate risk factors for MV but given the independent variables being used to predict the requirement for $\mathrm{MV}$ included baseline clinical features recorded during the first $24 \mathrm{~h}$ of ICU admission, those patients who were also mechanically ventilated during the first $24 \mathrm{~h}$ of admission were excluded from this univariate and multivariate logistic regression analysis.

Prior to analysis by linear regression, the PCS at hospital discharge was graphed as a histogram and quantilequantile (Q-Q) plot to assess the distribution of residuals and validate suitability for linear regression analysis. Simple linear regression was used to examine the dependency of PCS at hospital discharge by each of the independent variables in the dataset. Multiple linear regression was then used to model variables associated with PCS at hospital discharge. Variables that were identified to be significantly associated with PCS at hospital discharge in analysis by simple linear regression were all entered into the model using a backwards approach, dropping one least significant variable at a time. The model was then verified using a forward approach by introducing the variables sequentially. The distribution of the PCS at 3 months and 6 months post discharge were very skewed (Shapiro-Wilks normality tests $p$ values $<0.000001$ for 3 month and 6 month PCS) with mode values at the extreme of the range. Linear quantile was therefore used for analysis as this, unlike parametric methods, makes no assumptions about the distribution of the residuals. Using this method, the effect of independent variables on admission to ICU and features during ICU management were modelled on each specified quantile of $0.25,0.5$ and 0.75 (i.e. 1st quartile, median and 3rd quartile) of the respective dependent variables: 3-month post discharge PCS, and 6-month post discharge PCS. The threshold for significance was $p \leq 0.05$ (two-tailed). All analyses were carried out in Stata (StataCorp) version 16 and R Version 4.0.2 (R Corporation, Vienna).

This study was approved by the London School of Hygiene and Tropical Medicine (LSHTM) ethics committee, the Oxford Tropical Medicine Ethics Committee (OxTREC) and the local HTD ethics committee. All participants gave written informed consent prior to enrolment.

\section{Results}

One hundred eighty patients aged between 17 and 98 years, with generalised tetanus, were included in this study. A summary of the baseline features of the patients are described in Table 1 . Ninety of $180(50 \%)$ required MV for a median duration of 16.0 [IQR 12-24] days (Additional Files 1 \& 2). 
Table 1 Description of the demographic and clinical features of tetanus patients on admission to ICU

\begin{tabular}{|c|c|c|}
\hline & Physical outcome cohort $(N=80)$ & All $(n=180)$ \\
\hline Parameter & Median [IQR] or count (\%) & Median [IQR] or count (\%) \\
\hline \multicolumn{3}{|l|}{ Demographics } \\
\hline Age (years) & $49.0[35.0-59.5]$ & $51.0[40.5-62.0]$ \\
\hline Male sex & $64(80.0 \%)$ & $143(79.4 \%)$ \\
\hline Coexisting comorbidities & $22(27.5 \%)$ & $73(40.6 \%)$ \\
\hline \multicolumn{3}{|l|}{ Tetanus specific features } \\
\hline Deep wound & $2(2.5 \%)$ & $5(2.8 \%)$ \\
\hline Incubation period (days) & $8[6-11]$ & $8[7-13]$ \\
\hline Onset period (h) & $48[24-72]$ & $48[24-72]$ \\
\hline Time from first symptom to admission (days) & $3[2-5]$ & $3[2-5]$ \\
\hline History of difficulty breathing & $16(20.0 \%)$ & $37(20.6 \%)$ \\
\hline \multicolumn{3}{|l|}{ Clinical features during first $24 \mathrm{~h}$ of admission } \\
\hline Highest systolic blood pressure (mmHg) & 130 [120-140] & 140 [130-150] \\
\hline Highest heart rate (bpm) & 90 [82-98] & $93[84-104]$ \\
\hline Highest temperature $\left({ }^{\circ} \mathrm{C}\right)$ & $37.0[37.0-37.5]$ & $37.5[37.0-38]$ \\
\hline $\mathrm{SpO}_{2}$ on admission (\%) & 97 [96-98] & 97 [95-98] \\
\hline \multicolumn{3}{|l|}{ Ablett score:* } \\
\hline 1 & $17(21.3 \%)$ & $36(20 \%)$ \\
\hline 2 & $49(61.3 \%)$ & 116 (64.4\%) \\
\hline 3 & $13(16.3 \%)$ & 27 (15\%) \\
\hline 4 & $1(0.6 \%)$ & $1(0.6 \%)$ \\
\hline
\end{tabular}

*Ablett score: Grade 1 no spasms, grade 2 mild spasms not interfering with respiration, grade 3 spasms interfering with respiration and grade 4: grade 3 with clinical signs of autonomic nervous system dysfunction [19]

\section{Associations of admission features with disease severity} After removing the 16 patients who were mechanically ventilated during the first $24 \mathrm{~h}$ of admission (including 2 patients who died), data from 164 patients were available for analysis, of whom 74 (45.1\%) patients required MV and $3(1.8 \%)$ died. The features on ICU admission associated with MV after $24 \mathrm{~h}$ admission in univariate analysis are shown in Table 2.

Multivariate logistic regression analysis showed that the following admission variables were associated with increased odds of requiring MV: increased age (OR 1.03, 95\% CI 1.00-1.05, $p=0.04$ ), temperature (OR 2.10, 95\% CI $1.02-4.58, p=0.04)$ and HR (OR 1.04, 95\% CI 1.01$1.07, p=0.02$ ); and lower $\mathrm{SpO}_{2}$ (OR 0.80, 95\% CI 0.66$0.94, p=0.02)$ and shorter time from first symptom to admission (OR 0.65, 95\% CI 0.52-0.79, $p<0.001$ ).

Analysis of features present at ICU admission and associated with the development of the ANSD was performed on data from 177 participants after removing 1 patient with ANSD on admission to ICU and 2 patients with missing data. In this group, 43 (24.3\%) developed ANSD. The features present at ICU admission and associated with the development of ANSD in univariate analysis after excluding the one patient who had ANSD on admission are shown in Table 3.
Multivariate analysis showed similar admission features were associated with the development of ANSD as with MV. There was strong evidence of an association between the development of ANSD with time from the first symptom to admission (OR 0.64, 95\% CI 0.48-0.80, $p<0.01$ ) and maximum HR during the first day of admission (OR 1.03, 95\% CI 1.01-1.06, $p=0.004$ ). There was some evidence of an association between $\mathrm{SpO} 2$ on admission to ICU and development of ANSD (OR 0.95, 95\% CI 0.90-0.10, $p=0.04$ ).

\section{Physical functioning at discharge}

Eighty patients with generalised tetanus admitted to the ICU at HTD between August 2016 and June 2017 had a physical function at discharge data available and were included in the subgroup analysis. The median [IQR] PCS at hospital discharge was 32.37 [24.95-41.57].

The association of independent admission features with PCS at hospital discharge are shown in Additional File 3. Independent admission features associated with PCS at hospital discharge include age, female sex, presence of comorbidities, platelet count and HR during the first $24 \mathrm{~h}$ of admission. The association of independent features during ICU admission with PCS at hospital discharge are shown in Additional File 4. Independent 
Table 2 Tetanus risk factors for mechanical ventilation $(n=164)$

\begin{tabular}{|c|c|c|c|c|c|}
\hline \multirow[t]{2}{*}{ Parameter } & No MV $(n=90)$ & $M V(n=74)$ & OR for MV & $95 \% \mathrm{Cl}$ & $P$ value \\
\hline & \multicolumn{5}{|c|}{$\begin{array}{l}\text { Median [IQR], mean } \\
( \pm \text { SD) or count }(\%)\end{array}$} \\
\hline Age (years) & $46[37-59]$ & $52.5[43-65]$ & 1.027 & $1.01-1.05$ & 0.01 \\
\hline Male sex & $72(80.0 \%)$ & $60(81.1 \%)$ & 1.07 & $0.49-2.36$ & 0.86 \\
\hline Any comorbidities & $30(33.3 \%)$ & $34(45.9 \%)$ & 1.70 & $0.90-3.22$ & 0.10 \\
\hline Deep wound & $2(2.2 \%)$ & $2(2.7 \%)$ & 1.22 & $0.14-10.39$ & 0.84 \\
\hline Incubation period (days) $(n=122)$ & $10[7-14]$ & $8[6-11]$ & 0.99 & $0.952-1.04$ & 0.78 \\
\hline Period of onset $(h)(n=141)$ & 48 [24-72] & $48[24-48]$ & 0.98 & $0.97-0.99$ & 0.004 \\
\hline $\begin{array}{l}\text { Time from first symptom to admission } \\
\text { (days) }(n=162)\end{array}$ & $4[3-6]$ & $3[2-4]$ & 0.74 & $0.62-0.86$ & $<0.001$ \\
\hline History of difficulty breathing & $10(11.1 \%)$ & 19 (25.7\%) & 2.76 & $1.22-6.62$ & 0.02 \\
\hline \multicolumn{6}{|c|}{ Clinical Features during first $24 \mathrm{~h}$ of admission } \\
\hline Highest SBP (mmHg) & $136[120-150]$ & $140[130-147.5]$ & 1.01 & $0.99-1.03$ & 0.38 \\
\hline Highest heart rate (bpm) & 90 [82-99.5] & $97[88-111.5]$ & 1.05 & $1.03-1.08$ & $<0.001$ \\
\hline Heart rate range (bpm) & $12[8-20]$ & 16 [10-26] & 1.05 & $1.02-1.08$ & 0.001 \\
\hline Highest temperature $\left({ }^{\circ} \mathrm{C}\right)$ & $37.4[37.0-37.6]$ & $37.5[37.0--38.0]$ & 2.35 & $1.36-4.28$ & 0.003 \\
\hline $\mathrm{SpO}_{2}(\%)$ & 97 [96-98] & 96 [94-97] & 0.82 & $0.700-0.93$ & 0.01 \\
\hline SOFA $^{*}$ score $=0$ & $83(92.2 \%)$ & $52(70.3 \%)$ & Ref. & & \\
\hline SOFA $^{*}$ score $>=1$ & $7(7.8 \%)$ & $22(29.7 \%)$ & 5.02 & $2.09-13.45$ & 0.001 \\
\hline Urine output (ml/h) & $69.7[42.2-125.5]$ & $76.6[42.9-113.3]$ & 1.00 & $0.10-1.00$ & 0.81 \\
\hline Creatinine $(\mu \mathrm{mol} / \mathrm{L})$ & $78.9( \pm 16.4)$ & $90.9( \pm 48.4)$ & 1.01 & $1.00-1.03$ & 0.04 \\
\hline Platelets $\left(\times 10^{9} / \mathrm{L}\right)$ & $283.6( \pm 81.7)$ & $282.8( \pm 97.4)$ & 1.00 & $1.00-1.00$ & 0.96 \\
\hline Potassium (mEq/L) $(n=94)$ & $3.6( \pm 0.4)$ & $3.7( \pm 0.6)$ & 1.59 & $0.72-3.75$ & 0.27 \\
\hline White blood count $\left(\times 10^{9} / L\right)(n=95)$ & $9.6[7.1-11.0]$ & $10.2[8.4-13.0]$ & 1.15 & $1.02-1.34$ & 0.04 \\
\hline
\end{tabular}

*Sequential organ failure score [20]. Descriptive statistic describe number of patients with SOFA score $=0$ (reference) or $>=1$

variables significantly associated with PCS at hospital discharge included the requirement for tracheostomy and duration of tracheostomy requirement, requirement for MV, development of ANSD, development of any HAI, duration of ICU admission and duration of hospital admission.

The features associated with PCS at hospital discharge in the multiple regression analysis were age $(\beta-0.20$, $95 \%$ CI $-0.31,-0.09, p<0.001)$, duration of ICU admission in days $(\beta-0.22,95 \% \mathrm{CI}-0.40,-0.05, p=$ $0.01)$ and the development of at least one HAI $(\beta-4.62$, 95\% CI - 9.26, 0.02, $p=0.05$ ).

\section{Physical functioning at 3 and 6 months}

Median PCS at 3 months and 6 months post discharge were 53.0 [IQR 41.6-56.3] and 54.8 [IQR 51.6-57.3], respectively. Features associated with PCS in participants in the lowest functioning quantile $(0.25)$ are shown in Tables 4 and 5. Admission features of the female sex, age, $\mathrm{SpO}_{2}$ and highest systolic blood pressure were significantly associated with PCS at 6 months post discharge in this quantile. Management features strongly associated with PCS at 6 months after discharge in the lowest quantile PCS included MV, development of ANSD, development of HAI, bacteraemia, ventilatorassociated pneumonia, pressure ulcer, length of ICU and hospital stay (Table 5).

In those with highest quantile PCS (0.75 quantile), ventilator-associated pneumonia was associated with reduced PCS at both 3 and 6 months after hospital discharge $(\beta-3.32[95 \% \mathrm{CI}-0.34,0.00], p=0.002 ; \beta-$ 2.61 [95\% CI $-2.61,18.00], p<0.001$, respectively), and female sex at 6 months $(\beta-5.20$ [95\% CI -5.57 , 3.21], $p=0.04)$.

\section{Discussion}

We present data from a large contemporary series of patients with tetanus. Despite low mortality rates, our patients required long periods in ICU and developed severe tetanus with respiratory compromise and ANSD. Risk factors identified for these were similar to those previously identified for mortality $[6,21]$. Whilst some variables such as $\mathrm{SpO}_{2}$, were novel, dyspnoea noted by admitting doctors is a recognised prognostic feature and we believe $\mathrm{SpO}_{2}$ represents a more objective measure of respiratory compromise [21]. The similarity between the 
Table 3 Tetanus risk factors for development of ANSD $(n=179)$

\begin{tabular}{|c|c|c|c|c|c|}
\hline \multirow[t]{2}{*}{ Parameter } & No ANSD $(n=135)$ & ANSD $(n=44)$ & OR for ANSD & $95 \% \mathrm{Cl}$ & $P$ value \\
\hline & \multicolumn{5}{|l|}{$\begin{array}{l}\text { Median [IQR], mean } \\
( \pm \text { SD) or count }(\%)\end{array}$} \\
\hline Age (years) & $49[40-61]$ & $52.5[45-68.5]$ & 1.02 & $0.10-1.04$ & 0.08 \\
\hline Male sex & $108(80 \%)$ & $35(79.5 \%)$ & 0.97 & $0.429-2.37$ & 0.95 \\
\hline Any comorbidities & $51(37.8 \%)$ & $21(47.7 \%)$ & 1.50 & $0.75-3.00$ & 0.24 \\
\hline Deep wound & $3(2.2 \%)$ & $1(2.3 \%)$ & 1.02 & $0.05-8.23$ & 0.98 \\
\hline Incubation period (days) $(n=134)$ & $10[7-14]$ & $7[5-10]$ & 0.10 & $0.95-1.04$ & 0.83 \\
\hline Period of onset $(h)(n=156)$ & $48[24-72]$ & $24[24-48]$ & 0.98 & $0.96-0.99$ & 0.004 \\
\hline Time from first symptom to admission (days) $(n=177)$ & $4[3-5]$ & $2[2-3]$ & 0.69 & $0.54-0.85$ & 0.001 \\
\hline History of difficulty breathing & $23(17.0 \%)$ & $14(31.8 \%)$ & 2.27 & $1.03-4.92$ & 0.04 \\
\hline \multicolumn{6}{|l|}{ Clinical Features during first $24 \mathrm{~h}$ of admission } \\
\hline Highest SBP (mmHg) & $140[125-150]$ & $140[130-150]$ & 1.02 & $1.00-1.04$ & 0.02 \\
\hline Highest heart rate (bpm) & 92 [84-100] & $96[88-120]$ & 1.03 & $1.01-1.05$ & 0.002 \\
\hline Heart rate range (bpm) & $14[8-22]$ & 16 [10-28] & 1.02 & $0.99-1.05$ & 0.06 \\
\hline Highest temperature $\left({ }^{\circ} \mathrm{C}\right)$ & $37.4[37-37.8]$ & $37.5[37.2-38.0]$ & 1.46 & $0.850-2.49$ & 0.16 \\
\hline $\mathrm{SpO}_{2}(\%)$ & 97 [96-98] & 96 [93-98] & 0.96 & $0.90-1.00$ & 0.08 \\
\hline \multicolumn{6}{|l|}{ SOFA score: } \\
\hline 0 & $115(85.2 \%)$ & $31(70.5 \%)$ & Ref. & & \\
\hline$>=1$ & $20(14.8 \%)$ & $13(29.5 \%)$ & 2.41 & $1.06-5.36$ & 0.03 \\
\hline Urine output (ml/h) & 71 [43-123] & $77.5[42-110]$ & 1.00 & $0.99-1.00$ & 0.62 \\
\hline \multicolumn{6}{|l|}{ Ablett on admission: } \\
\hline 1 & $34(25.2 \%)$ & $2(4.5 \%)$ & Ref. & & \\
\hline 2 & $83(61.5 \%)$ & $33(75.0 \%)$ & 6.76 & $1.90-43.12$ & 0.011 \\
\hline 3 & $18(13.3 \%)$ & $9(20.5 \%)$ & 8.50 & $1.94-59.82$ & 0.010 \\
\hline Creatinine $(\mu \mathrm{mol} / \mathrm{L})$ & $82.6( \pm 32.3)$ & $96.5( \pm 58.9)$ & 1.01 & $1.00-1.02$ & 0.08 \\
\hline Platelets $\left(\times 10^{9} / \mathrm{L}\right)$ & $281.4( \pm 85.1)$ & $289.5( \pm 99.6)$ & 1.01 & $1.00-1.00$ & 0.60 \\
\hline Potassium (mEq/L) $(n=99)$ & $3.6( \pm 0.5)$ & $3.7( \pm 0.6)$ & 1.493 & $0.64-3.53$ & 0.35 \\
\hline White blood count $\left(\times 10^{9} / \mathrm{L}\right)(n=100)$ & $9.7[7.1-11.3]$ & $10.9[8.6-14.2]$ & 1.167 & $1.04-1.34$ & 0.02 \\
\hline
\end{tabular}

risk factors we have identified and those identified for mortality supports their use as alternative markers of disease severity or study end-points in settings such as ours where mortality is low [22].

Our study is limited by the risk factors available for consideration, and sample size to look at smaller subpopulations. Data selection was based on published literature, including a large case series previously at our hospital. It is possible therefore that important factors were not identified or simplified markers. For example, we used a simple classification of wounds as superficial or deep based on a previous case series of 100 patients in our centre (3). Additionally, we have not included factors such as possible vaccination history. No patients reported knowledge of receiving tetanus vaccination and anti-tetanus toxoid antibodies from patients in the 2018 cohort were measured and shown to be sub-protective (reported elsewhere) but it is possible that some patients may have received some previous immunisation in infancy and had low (sub-protective) antibody levels. The Expanded Programme on Immunization was introduced into Vietnam in 1981, and since 1994 has consistently reported high coverage (90-99\%) for DTP3 Similarly 89-93\% for maternal vaccination [23]. It is therefore possible that particularly the younger patients may have received vaccination in infancy.

Our data on physical function at hospital discharge, 3 months post discharge and 6 months post discharge demonstrates that most of this relatively young and middle-aged population regains normal functioning after a severe illness has resolved. We identified age and prolonged hospital stay as the principal indicators of worse physical functioning at hospital discharge with HAI nonsignificantly associated. In those with the lowest PCS measures 6 months post hospital discharge many factors were significantly associated with reduced physical 
Table 4 The association between independent features on ICU admission and 25th quantile physical function at 3 months and 6 months post discharge

\begin{tabular}{|c|c|c|c|c|}
\hline & \multicolumn{2}{|l|}{$\begin{array}{l}3 \text { months } \\
N=75\end{array}$} & \multicolumn{2}{|l|}{$\begin{array}{l}6 \text { months } \\
N=69\end{array}$} \\
\hline & $\beta(95 \% \mathrm{Cl})$ & $P$ value & $\beta(95 \% \mathrm{Cl})$ & $P$ value \\
\hline Female sex & $-18.00(-26.58,-10.33)$ & 0.002 & $-20.21(-23.04,-10.13)$ & $<0.001$ \\
\hline Age & $-0.46(-0.53,-0.37)$ & $<0.001$ & $-0.270(-0.37,-0.26)$ & $<0.001$ \\
\hline Any pre-existing comorbidities & $-15.28(-23.85,-7.30)$ & 0.003 & $-11.36(-17.81,-1.39)$ & 0.07 \\
\hline Incubation period $(n=50)$ & $0.69(-1.137,1.41)$ & 0.19 & $0.17(-0.01,0.42)$ & 0.31 \\
\hline Period of onset $(n=55)$ & $0.06(-0.13,0.10)$ & 0.32 & $0.06(-0.22,0.08)$ & 0.11 \\
\hline Time from 1st symptom to admission & $1.19(-1.64,2.10)$ & 0.19 & $0.70(-1.17,1.25)$ & 0.13 \\
\hline Difficulty breathing on admission & $-9.61(-14.91,8.08)$ & 0.18 & $-3.00(-16.57,0.08)$ & 0.35 \\
\hline \multicolumn{5}{|l|}{ Clinical Features during first $24 \mathrm{~h}$ of admission } \\
\hline Highest systolic blood pressure $(\mathrm{mmHg})^{*}$ & $-0.21(-0.48,-0.15)$ & 0.07 & $-0.21(-0.27,0.02)$ & 0.01 \\
\hline Highest heart rate (bpm) & $-0.08(-0.38,0.20)$ & 0.64 & $-0.08(-0.40,-0.01)$ & 0.18 \\
\hline Heart rate range $(\mathrm{bpm})^{*}$ & $-0.07(-0.42,0.30)$ & 0.70 & $-0.13(-0.31,0.01)$ & 0.19 \\
\hline Highest temperature $\left({ }^{\circ} \mathrm{C}\right)$ & $5.07(-7.16,8.76)$ & 0.16 & $1.97(-13.28,3.17)$ & 0.23 \\
\hline SpO2 on admission (\%)* & $0.55(0.40,3.81)$ & 0.21 & $0.72(0.00,3.26)$ & 0.03 \\
\hline $\begin{array}{l}\text { SOFA }^{* *} \text { score }^{1 *} \\
0 \\
>=1\end{array}$ & $-6.17(-17.98,-0.01)$ & 0.27 & $-3.97(-17.98,-0.85)$ & 0.82 \\
\hline Urine output (ml/h) & $0.04(-0.14,0.04)$ & 0.20 & $0.01(-0.02,0.03)$ & 0.34 \\
\hline Creatinine $(\mu \mathrm{mol} / \mathrm{L})$ & $0.16(-0.06,0.27)$ & 0.23 & $0.01(-0.07,0.17)$ & 0.93 \\
\hline Platelets $\left(\times 10^{9} / \mathrm{L}\right)$ & $-0.06(-0.10,-0.04)$ & 0.01 & $-0.03(-0.08,0.00)$ & 0.13 \\
\hline
\end{tabular}

'SOFA score of 0 is the baseline group

*During the first $24 \mathrm{~h}$ of hospital admission

**Sequential organ failure score [20]

Table 5 The association between independent features during ICU management and 25th quantile PCS at 3 months and 6 months post discharge

\begin{tabular}{|c|c|c|c|c|}
\hline & \multicolumn{2}{|l|}{3 months } & \multicolumn{2}{|l|}{6 months } \\
\hline & $\beta(95 \% \mathrm{Cl})$ & $P$ value & $\beta(95 \% \mathrm{Cl})$ & $P$ value \\
\hline Tracheostomy required & $-9.69(-17.61,-2.65)$ & 0.06 & $-6.80(-17.31,-0.73)$ & 0.08 \\
\hline Duration tracheostomy (days) $(n=30)$ & $-0.47(-2.00,-0.34)$ & 0.16 & $-0.72(-1.49-0.38)$ & 0.25 \\
\hline Mechanical ventilation required & $-9.06(-17.56,2.29)$ & 0.10 & $-11.36(-18.19,-0.55)$ & 0.02 \\
\hline Duration mechanical ventilation (days) $(n=27)$ & $-0.33(-1.37,0.08)$ & 0.38 & $-0.36(-1.30,-0.22)$ & 0.25 \\
\hline Autonomic nervous system disturbance & $-13.52(-18.22,-8.84)$ & 0.02 & $-15.65(-19.29,-4.70)$ & 0.001 \\
\hline Duration diazepam required (days) $(n=66)$ & $0.51(0.35,0.80)$ & 0.01 & $0.26(0.10,0.69)$ & 0.07 \\
\hline Duration midazolam required (days) $(n=40)$ & $-0.39(-0.87,0.21)$ & 0.31 & $-0.61(-1.28,0.02)$ & 0.02 \\
\hline Duration Magnesium sulphate (days) $(n=14)$ & $2.06(-7.73,2.79)$ & 0.10 & $0.73(-8.58,1.57)$ & 0.53 \\
\hline Duration pipecuronium (days) $(n=22)$ & $-0.97(-1.15,1.33)$ & 0.29 & $-0.69(-0.93,0.90)$ & 0.35 \\
\hline Ventilator-associated pneumonia* & $-1.80(0.00,-0.153)$ & 0.09 & $-2.24(-17.98,-1.92)$ & 0.001 \\
\hline Bacteraemia* & $-12.34(-28.53,-1.00)$ & 0.14 & $-14.51(-25.34,-2.13)$ & 0.03 \\
\hline Urinary tract infection* & $-10.46(-15.11,9.99)$ & 0.21 & $-11.12(-17.20,-0.44)$ & 0.12 \\
\hline Any healthcare associated infection & $-13.33(-17.92,-3.51)$ & 0.03 & $-15.73(-20.04,-4.05)$ & 0.001 \\
\hline Pressure ulcer & $-12.51(-17.98,7.59)$ & 0.25 & $-20.28(-17.98,-14.713)$ & $<0.001$ \\
\hline Length of ICU stay (days) & $-0.52(-0.91,-0.29)$ & 0.02 & $-0.56(-0.61,-0.32)$ & 0.004 \\
\hline Length of hospital stay (days) & $-0.64(-0.82,-0.30)$ & 0.02 & $-0.48(-0.70,-0.34)$ & 0.01 \\
\hline
\end{tabular}


functioning. Multivariate analysis was not possible due to small numbers in our sample; however, it is likely that many of these features are indicative of severe disease or prolonged treatment in ICU. Interestingly neither duration of ventilation, tracheostomy or pipecuronium appeared to be strongly associated with reduced PCS at 3 or 6 months after discharge. This may indicate that other events, such as HAI which are also associated with prolongation of ICU and hospital stay, are more important determinants of outcome. Age and HAI were factors we have previously identified as significant contributors to increased muscle wasting during hospitalisation and were are independent of the duration of hospital length of stay [14]. We believe this study serves as further evidence that preventing muscle wasting should be a priority in improving functional outcome in critically ill patients. HAI remains a modifiable factor associated with this, and as we observed that even in those with highest physical function, ventilator associated pneumonia remained a predictor of PCS.

The only available Vietnamese SF-36 data is from a group of Vietnamese migrants to Australia which cannot be generalised to the entire Vietnamese population [24] and the lack of data regarding the use of SF-36 in the Vietnamese population is a significant limitation of our study. In lieu of robust population standard normative data, we used American population data. Additionally, whilst we used an accepted algorithm to calculate the PCS, it remains unclear whether other algorithms may be superior due to assumptions about the relationship between physical and mental health scale componentsalso unknown in the Vietnamese population [25]. Our results, however, are in agreement with previous individual scale analysis and by using a single component score we reduce concerns related to statistical power and multiple testing [14]. By publishing data from Vietnamese adults, we are able to contribute towards a better understanding of SF-36 in this population.

\section{Conclusions}

We observed that risk factors for MV, development of ANSD and reduced physical functioning were consistent with existing knowledge and findings in settings of low mortality. These outcomes may therefore be suitable endpoints against which to evaluate therapeutic interventions. Risk factors for reduced functional outcome at 3 months and 6 months post discharge suggest that modifiable features during hospitalisation are important determinants of long-term outcome.

Tetanus remains, however, a vaccine-preventable disease and improved preventative strategies should continue to be central to reducing morbidity and mortality from this disease.

\section{Abbreviations}

ANSD: Autonomic nervous system dysfunction; HAl: Hospital-acquired infection; HTD: Hospital for Tropical Diseases, Ho Chi Minh City, Vietnam; ICU: Intensive care unit; IP: Incubation period; LMIC: Low- and middle-income countries; MV: Mechanical ventilation; OP: Onset period; PCS: Physical component summary score of the RAND 36-item Short Form Health Survey; SF-36: RAND 36-item Short Form Health Survey; SOFA: Sequential organ failure assessment score; $\mathrm{SpO}_{2}$ : Peripheral capillary oxygen saturation; WHO: World Health Organization

\section{Supplementary Information}

The online version contains supplementary material available at https://doi. org/10.1186/s41182-021-00336-w.

Additional file 1. Study Flowchart.

Additional file 2. Flowchart of respiratory management.

Additional file 3. The association between independent features on ICU admission and SF 36 physical function composite score at hospital ( $n=$ 79).

Additional file 4. The association between independent features during ICU management and SF 36 physical function composite score at hospital discharge $(n=79)$.

Acknowledgements

Staff in adult ICU and Ward D at the Hospital for Tropical Diseases, Ho Chi Minh City.

Authors' contributions

RDF, CLT, NVH and LMY conceived the study. TNT, LMY, LVT, JC, TTT, ZP, NVH and CLT designed the study. TNT, NVTD, VTNT, PHTN, NTKA, PTL, DBT, NTP, NTT, PBT, DTHT, TTDT, PTT and JC implemented the study. RDF and DDH performed the analyses. RDF, DDH, CLT, ZP and LMY drafted the manuscript. All authors reviewed the final version. The author(s) read and approved the final manuscript.

Funding

The study was funded by Wellcome Trust (107367/Z/15/Z and 089276/B/09/7)

Availability of data and materials

The dataset(s) supporting the conclusions of this article is(are) available in the Oxford University Research Archive (ORA).

\section{Declarations}

Ethics approval and consent to participate

The study was approved by the Ethics and Scientific Committee of the Hospital for Tropical Diseases and the Oxford Tropical Research Ethics Committee (OxTREC), and the ethics committee of the London School of Tropical Medicine. All subjects provided written informed consent before enrolment in the study.

Consent for publication

Not applicable

\section{Competing interests}

The authors declare that they have no competing interests.

\section{Author details}

${ }^{1}$ London School of Hygiene and Tropical Medicine, London, UK. ${ }^{2}$ Hospital for Tropical Diseases, Ho Chi Minh City, Vietnam. ${ }^{3}$ Oxford University Clinical Research Unit, Ho Chi Minh City, Vietnam. ${ }^{4}$ Kings College, London, UK. ${ }^{5}$ Gia Dinh Hospital, Da Nang City, Vietnam. ${ }^{6}$ University of Medicine and Pharmacy, Ho Chi Minh City, Vietnam. ${ }^{7}$ Centre for Tropical Medicine and Global Health, University of Oxford, Oxford, UK. ${ }^{8}$ William Harvey Research Institute, Barts and The London School of Medicine and Dentistry, Queen Mary University of London, London, UK. ${ }^{9}$ Royal London Hospital, London, UK. 
Received: 3 May 2021 Accepted: 24 May 2021

Published online: 21 June 2021

\section{References}

1. Yen LM, Thwaites CL. Tetanus. Lancet. 2019;393(10181):1657-68.

2. Trieu HT, Lubis IN, Qui PT, Yen LM, Wills B, Thwaites CL, et al. Neonatal tetanus in Vietnam: comprehensive intensive care support improves mortality rates. J Pediatric Infect Dis Soc. 2015;5(2):227-30.

3. Thwaites CL, Yen LM, Nga NTN, Parry J, Binh NT, Loan HT, et al. Impact of improved vaccination programme and intensive care facilities on incidence and outcome of tetanus in southern Vietnam, 1993-2002. Trans R Soc Trop Med Hyg. 2004;98(11):671-7.

4. Brauner JS, Vieira SRR, Bleck TP. Changes in severe accidental tetanus mortality in the ICU during two decades in Brazil. Intensive Care Med. 2002; 28(7):930-5.

5. da Nóbrega MVD, Reis RC, Aguiar ICV, Queiroz TV, Lima ACF, Pereira EDB, et al. Patients with severe accidental tetanus admitted to an intensive care unit in Northeastern Brazil: clinical-epidemiological profile and risk factors for mortality. Braz J Infect Dis. 2016;20(5):457-61.

6. Patel JC, Mehta BC. Tetanus: study of 8,697 cases. Indian J Med Sci. 1999;53: 393-401.

7. Cook TM, Protheroe RT, Handel JM. Tetanus: a review of the literature. $\mathrm{Br}$ J Anaesth. 2001;87(3):477-87

8. Woldeamanuel YW, Andemeskel AT, Kyei K, Woldeamanuel MW Woldeamanuel W. Case fatality of adult tetanus in Africa: Systematic review and meta-analysis. J Neurol Sci. 2016;368:292-9.

9. Miranda-Filho DDB, Ximenes RADA, Barone AA, Vaz VL, Vieira AG, Albuquerque VMG. Randomised controlled trial of tetanus treatment with antitetanus immunoglobulin by the intrathecal or intramuscular route. BMJ. 2004;328(7440):615.

10. Attygalle D, Rodrigo N. Magnesium sulphate for control of spasms in severe tetanusCan we avoid sedation and artificial ventilation? Anaesthesia. 1997; 52(10):956-62

11. Mahieu R, Reydel T, Maamar A, Tadié JM, Jamet A, Thille AW, et al. Admission of tetanus patients to the ICU: a retrospective multicentre study. Ann Intensive Care. 2017;7(1):112. https://doi.org/10.1186/s13613-017-0333-y.

12. Nakajima M, Aso S, Matsui H, Fushimi K, Yasunaga $H$. Clinical features and outcomes of tetanus: Analysis using a National Inpatient Database in Japan. J Crit Care. 2018:44:388-91.

13. Puthucheary ZA, Rawal J, McPhail M, Connolly B, Ratnayake G, Chan P, et al. Acute skeletal muscle wasting in critical illness. JAMA. 2013; 310(15):1591-600

14. Trung TN, Duoc NVT, Nhat LTH, Yen LM, Hao NV, Truong NT, et al. Functional outcome and muscle wasting in adults with tetanus. Trans R Soc Trop Med Hyg. 2019;113(11):706-13. https://doi.org/10.1093/trstmh/trz055.

15. Loan H, Yen L, Kestelyn E, Hao N, Than T, Dung N, et al. Intrathecal Immunoglobulin for treatment of adult patients with tetanus: A randomized controlled $2 \times 2$ factorial trial. Wellcome Open Res. 2018;3:58.

16. An VT, Khue PM, Yen L, D. PN, M S. Le tétanos à Hô-Chi-Minh-Ville, Vietnam : épidémiologie, clinique et pronostic, à propos de 389 cas à I ' Hôpital des maladies tropicales; 2015. p. 342-8.

17. Hofhuis JGM, Van Stel HF, Schrijvers AJP, Rommes JH, Spronk PE. Changes of health-related quality of life in critically ill octogenarians: A follow-up study. Chest. 2011;140(6):1473-83.

18. Ware JE, Kosinski M KS. SF-36 Physical and Mental Health Summary Scales. 1994;(May).

19. Ablett J, Ablett JJL. Analysis and main experiences in 82 patients treated in the Leeds Tetanus Unit. In: Symposium on tetanus in Great Britain Leeds: Leeds General Infirmary; 1967. p. 1-10

20. Vincent J-L, Moreno R, Takala J, Willatts S, De Mendonça A, Bruining H, et al, The SOFA (Sepsis.related Organ Failure Assessment) score to describe organ dysfunction/failure. Intensive Care Med. 1996;22 Springer-Verlag.

21. Thwaites CL, Yen LM, Glover C, Tuan PQ, Nga NTN, Parry J, et al. Predicting the clinical outcome of tetanus: the tetanus severity score. Trop Med Int Health. 2006;11(3):279-87.

22. Patel J, Mehta B, Modi K. Prognosis in tetanus. Indian J Med Sci. 1967;21(11): $181-201$.

23. Expanded Program on Immunizations. National EPI Review Report Vietnam. 2009.
24. Watkins RE, Plant AJ, Sang D, O'Rourke T, Gushulak B. Development of a Vietnamese version of the short form-36 health survey. Asia Pac J Public Health. 2000;12(2):118-23.

25. Laucis NC, Hays RD, Bhattacharyya T. Scoring the SF-36 in orthopaedics: A brief guide. J Bone Jt Surg Am Vol. 2014;97(19):1628-34.

\section{Publisher's Note}

Springer Nature remains neutral with regard to jurisdictional claims in published maps and institutional affiliations.
Ready to submit your research? Choose BMC and benefit from:

- fast, convenient online submission

- thorough peer review by experienced researchers in your field

- rapid publication on acceptance

- support for research data, including large and complex data types

- gold Open Access which fosters wider collaboration and increased citations

- maximum visibility for your research: over $100 \mathrm{M}$ website views per year

At BMC, research is always in progress.

Learn more biomedcentral.com/submissions 